\title{
The Impact of Integrating Project Studies into the Working Processes of Companies
}

\author{
Frank Fuchs-Kittowski ${ }^{1}$, Juliane Siegeris ${ }^{1} \&$ Jörn Freiheit ${ }^{1}$ \\ ${ }^{1}$ School of Computer Science, University of Applied Sciences (HTW) Berlin, Berlin, Germany. \\ Correspondence: Frank Fuchs-Kittowski, School of Computer Science, University of Applied Sciences (HTW) \\ Berlin, Berlin, Germany.
}

Received: May 8, 2020

Accepted: June 21, 2020

Online Published: June 24, 2020

doi:10.5430/ijhe.v9n4p244

URL: https://doi.org/10.5430/ijhe.v9n4p244

\begin{abstract}
This article describes and evaluates the concept of project studies in the part-time master's degree course "Professional IT-Business" at the HTW Berlin. The concept contains several elements which are intended to enable and support work process-integrated learning, or learning in real work processes and projects in companies. The concept presents as an innovative solution for competence development through project-oriented, work process-integrated forms of teaching and learning in cooperation between the university and companies. To evaluate the effectiveness of the concept of work-process-integrated project study, a survey among 31 students was carried out concurrently testing eight hypotheses. The descriptive analysis of the survey results allowed conclusions on the potential for change and improvement of the didactic concept underlying the project study. In addition to the description of the methodology and the results obtained, conclusions were drawn from the evaluations as well as perspectives on future applications of the work-process-integrated project study.
\end{abstract}

Keywords: project studies, in-service master program, evaluation, didactic concept, work-process-integrated courses

\section{Introduction}

Lifelong learning is essential in today's society because in order for learning to be successful throughout life - and thus at different places and in different institutions - permeability between learning and working institutions and places is of central importance. However, permeability, especially between the vocational and higher education sectors is often reduced to the crediting of competences acquired in the workplace (Freitag et al., 2011), especially during the transition from work to study, i.e. vertically (Buhr et al., 2008). The vertical permeability allows an advancement in the educational system. This term describes the steps from one qualification level to the next, e.g. from vocational training to higher education studies (Diller, 2010). In contrast to vertical permeability there is horizontal permeability. The horizontal permeability means the permeability at the same level of training, e.g. with the recognition of foreign degrees or the linking of formal (university) and competences acquired informally (at work). However, there has been limited potential in the horizontal permeability that can arise from the fact that students often work part-time or full-time. In doing so, they apply the knowledge and skills acquired at university in their workplace whilst simultaneously, acquiring new knowledge and skills at their work that they may not have applied to their university studies. In order to tap this potential, new concepts are needed to link the two learning locations of university and the workplace more closely.

In order to specifically promote students' vocational action competences and to integrate the learning location of companies, an innovative concept for the implementation of "project studies" within the framework of the part-time master's programme "Professional IT-Business" has been developed at the HTW Berlin (Fuchs-Kittowski et al., 2017): Students in project studies learn in the work process, in real projects in their companies. The students shape their learning at work whilst being supported comprehensively by personnel and technical resources. A process-oriented curriculum or reference project defines the learning objectives and structures the project studies. It is used to select the practical project, plan the work and learning processes and, finally, to provide evidence of successful project studies. All processes of the reference project must be demonstrably mastered through a process of reflection and documentation.

The paper explores the evaluation of the concept of work process-integrated project studies and examines the assumptions and the effectiveness of the concept to develop suggestions for optimization. 


\section{Concept of Project Studies Integrated into the Work Processes of Companies}

\subsection{Background}

Project-oriented forms of teaching and learning promote vocational competence (Kruse, 2009; Kleuker et.al., 2011), and feature in the curriculum of many degree programmes today (Liebehenschel, 2013). In addition, project studies are often already taking place directly in companies (Siegeris et.al., 2015). Students get to know a real working environment and take on tasks in real projects, which enables them to apply their acquired knowledge in practice and gain new experience (Lewerentz \& Rust, 2001). Here, learning is more strongly shifted to the real work process i.e. the work place as the learning location and is oriented towards real work tasks instead of fixed, prescribed contents /curriculum. Terms such as "learning by doing" or "trainee programme" describe concepts in the company context that are enacting this concept, thereby "learning in the work process" where students independently close knowledge gaps that occur during work, place self-organised learning processes and the development of action competence in the foreground.

The promotion of competences depends largely on the way in which the project-oriented teaching and learning events are organised and carried out. This depends in particular on three factors (Jung, 2009): i) the content and framework conditions of the project; ii) the teachers and their understanding of supervision; and iii) the students and their willingness to accept the challenges of project work.

When students work on projects in companies, a number of challenges also arise for students and teachers due to the different projects and framework conditions in the companies. Some of these challenges may include: how can project work and learning be sensibly combined, how can the achievement of learning goals and competence development be ensured, and how can students be adequately supported in project work?

In order to specifically promote students' competence to act, an innovative concept for "project studies" has been developed at the HTW Berlin within the master's programme "Professional IT-Business".

\subsection{Concept}

The concept for the course "project studies" focusses on the integration of learning under real conditions, in real projects in companies systematising and supporting these learning processes as part of the work process in real projects involves three main concepts: a) Process-oriented curricula or "reference projects"; b) A strategy for learning in the work process or "practical projects"; and c) Organisational and technical instruments to support students (Fuchs-Kittowski et al., 2017)

A process-oriented curriculum or reference project, specifies the learning objectives and structures the project study. It serves for the selection of the practical project, the planning of the work and learning processes, and the proof of the successful project study. All processes of the reference project must be demonstrated by mastering, reflecting, and documenting them. Students do not take examinations of the conventional type but are assessed on the basis of the documentation they produce on the completion of the work processes in accordance with the reference project.

Learning processes are initiated by challenges or knowledge gaps in a real project and students are required to cope with these self-directed challenges. This may involve-a number of sub-processes which are typical tasks for the profile in question e.g. that of a data analyst, as described in a "reference project" which forms the process-oriented curriculum and defines the learning outcomes.

Students receive support for their self-directed work on the practical project from personnel in various roles, such as an expert advisor, learning process tutor, line-manager, and colleagues or fellow students. Technical or media support is provided to students in the form of a learning platform, which supports learning and working independently of time and place, and also makes it possible to provide individualised supervision. Additionally, in the preceding semester the students attend a classic lecture course with tutorial in which the required specialised knowledge is taught e.g. for data analytics.

\subsection{Hypotheses}

With the aim of empirically testing the basic assumptions of the concept of work-process-integrated project studies, eight hypotheses were formed on the three sub-areas of conception: (1) the role of process-oriented curricula (reference projects); 2) learning in the work process (practice projects); and 3) personnel, technical and professional support of learning in the work) as well as on the general acceptance of project studies (overall evaluation).

H1: Reference projects are a good aid for identifying \& selecting suitable practical projects:

The research hypothesised that the reference project offers an important orientation and support aid for the identification and selection of practical projects. 
$\mathrm{H} 2$ : Reference projects help with structured learning in the practical projects:

The research hypothesised that the reference project is an important orientation and structuring aid for learning in the practical projects.

H3: Learning and working in practical projects leads to the acquisition of professional competencies to act:

The research hypothesised that by learning and working in the practical projects, the students would acquire the necessary skills for the work profile.

H4: The students develop the ability to learn self-directed:

The research hypothesised that the students would become better able to learn independently and self-directed.

H5: Personnel in various roles offer support for the self-controlled learning of the students:

The research hypothesised that various roles (learning process tutor, expert advisors, line managers, and fellow students and colleagues) were a key source of support for the self-controlled learning process of the students.

H6: Support for the self-controlled learning by IT support (e-learning environment):

The research hypothesised that the e-learning environment provides important support for learning.

H7: Self-controlled learning is supported by a basis of specialist knowledge:

The research hypothesised that the classic lectures on the field of the practical projects in the previous semester provided important specialist support for learning and completion of the practical projects.

H8: Acceptance of the project studies:

The research hypothesised that project studies are an attractive form of teaching for the students (acceptance hypothesis).

\section{Methodology}

An evaluation serves the retrospective examination of outcomes so that, on this basis, processes can be adapted and optimised (Götz, 1993). The main goal of the evaluation of the project studies was the assessment of the viability of the underlying assumptions and the efficacy of the concept of project studies integrated in the work process.

Evaluation here is understood as the practically-oriented assessment of the project studies using empirical methods (Wottawa \& Thierau, 1990). Therefore, eight hypotheses were formulated from the three concepts, and indicators were specified for each hypotheses. On the basis of these indicators, the survey instruments were developed, applied, and evaluated. Experience gained in the course of the project studies was also drawn on when interpreting the results (cf. Brand, 2014; Mattauch \& Kubath, 2005).

\subsection{Data Survey}

In October 2019, the SurveyMonkey questionnaire was distributed online to 31 students: 16 students from the current 3rd Semester, and 15 students who had participated a year earlier. The responses were anonymised.

\subsection{Data Evaluation}

Responses were received from 20 students (response rate: 64.5\%)-and the data were evaluated using the SurveyMonkey online survey tool. In view of the relatively small group size, application of parametric analysis methods were inappropriate so the data underwent a descriptive analysis (REF) of the data, with absolute values and percentage distributions.

\subsection{Participants}

Of the 20 respondents, 12 had completed the "Data Analyst" profile in the summer semester, and had just started the 3rd semester. The eight students in the previous cohort has been able to choose in the summer semester 2019 between the profiles "Software Developer" (2), "IT Project Coordinator" (3), and "IT Solution Developer" (3). 
Nearly half the respondents had worked in the IT sector for 2 or 3 years before beginning the master's degree course

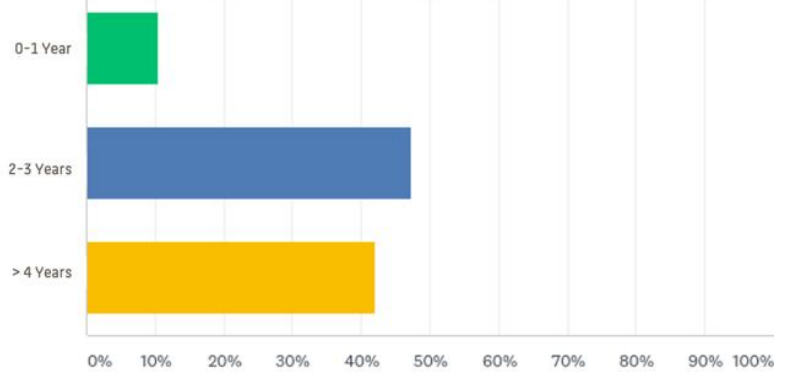

at HTW Berlin (47.37 \%, n=9/19), and almost as many had already worked for 4 years or more $(42.11 \%, \mathrm{n}=8 / 19)$; only two began the course with less work experience $(10.53 \%, \mathrm{n}=2 / 19)$.

Figure 1. Work experience before studying

\subsection{Statistical Validity}

In view of the small sample size $(n=20)$, the statistical validity is limited. The responses cannot be assumed to be fully representative, and the findings may only be applicable to a limited extent under other conditions (different companies or regional settings, etc.). However, the survey data do give an initial indication of the stability of the concept.

\section{Results}

Eight hypotheses were formulated about the basic principles of the concept, and suitable indicators were defined for each of these.

\subsection{Hypothesis 1: Reference Projects are A Good Aid for Identifying and Selecting Suitable Practical Projects}

The research hypothesised that the reference project offered an important orientation and support aid for the identification and selection of practical projects. The students were asked "On the basis of the sub-processes described in the reference project, was it possible to identify a practical project that was suitable for the project studies?".

Almost all respondents were able to find a suitable practical project. For $30 \%$ of the respondents this was "No problem at all" ( $\mathrm{n}=6)$ and for $40 \%$ it was "Relatively easy without much effort" $(\mathrm{n}=8)$. While $25 \%$ of the respondents had "Considerable trouble and effort" $(\mathrm{n}=5)$, only one respondent $(5 \%)$ was "Unable to find any suitable practical project" ( $\mathrm{n}=1)$. The unsuccessful individual could not find a project for the "Data Analyst" profile, and this can indeed prove difficult, because not all companies have involved themselves in data analytics.

Typical reasons cited by students for the difficulties they encountered were:

"Data was not available in sufficient quantity/quality, data protection."

"In the company department, the relevant profile (here a data analyst) was not part of daily operations."

"It was difficult to implement the planned theoretical derivation in the project at work because the company had different procedures."

In summary, the reference projects provide important support for the identification of practical projects, but problems were encountered if neither the company nor its customers were carrying out projects with the necessary profile. For further support in the selection of the practical projects it therefore seems appropriate in future to increase the number of possible reference projects and open up the selection across all semesters.

\subsection{Hypothesis 2: Reference Projects Help with Structured Learning in the Practical Projects}

The research hypothesised that the reference project is an important orientation and structuring aid for learning in the practical projects. We asked "How helpful did you feel the reference project was for carrying out the practical project?", and "Is it planned to use the reference project for structuring future work or similar projects?".

Just less than half the respondents $(40 \%, \mathrm{n}=8)$ said that the reference project was "Mostly helpful" for carrying out the practical project. For $35 \%$ it was "Somewhat helpful" ( $n=7)$ and for $15 \%$ "Very helpful" ( $n=3)$. Only two students said that the reference project was "Not at all helpful" (10\%). One of these students had not been able to find a project, and the other had seen no other option, and had accepted the project with the intention of completing it with 
"as little additional effort as possible".

A relatively small proportion of the respondents planned to use the reference project in future for structuring work or similar projects, and a third of respondents did not. But the largest proportion said they did not know yet. Since the reference project was at least "helpful" for a large majority of respondents, this can be explained by the fact that the students are already working in a fixed position in the company, and they are uncertain whether they will be working with the topics of the reference projects in future. In addition, they may feel that they have now grasped the reference processes, so that they will no longer need this aid in future.

In summary, the reference project was appreciated by the large majority of respondents as an aid for orientation and structuring of the practical projects. It offered important support for the practical projects and two-thirds did not rule out using it as a structuring aid in future.

\subsection{Hypothesis 3: Learning and Working in Practical Projects Leads to the Acquisition of Skills Related to the Work Profile}

The research hypothesised that by learning and working in the practical projects, the students would acquire the necessary skills for the work profile.

The students were asked "How much were you able to learn in the project studies in the following sectors: 'Special field', 'Methodology', 'Social', and 'Personal'". More than half of the respondents (55\%), said that in their special field they had learnt "much" $(50 \%, \mathrm{n}=10)$ or "very much" $(5 \%, \mathrm{n}=1)$. In the field of methodological skills, similar numbers $(60 \%)$ said that they had learnt "much" $(50 \%, n=10)$ or "very much" $(10 \%, n=2)$. Surprisingly, in the case of social skills all respondents said that they had learnt either "nothing" $(35 \%, n=7)$ or "little" $(65 \%, n=13)$. A reason for this could be that since the students are integrated in a company, they would have participated in projects and had opportunities to gain social skills even without the project studies. Also, only $30 \%$ of the respondents $(n=6)$ said that they had learnt "much" in the field of personal skills.

After concluding the project studies, students felt well prepared for their activity profile (Data Analyst, IT-Project-Coordinator, IT-Solution-Developer, Software Developer) or for future work tasks. When asked "To what extent has the practical project helped you deal with typical work processes of your profile better than before?", a clear majority $(70 \%)$ responded either "very much" $(10 \%, \mathrm{n}=2)$ or "mostly" $(60 \%, \mathrm{n}=12)$. Only a minority of $30 \%$ $(n=6)$ said that the practical project had helped either "little" $(20 \%, n=4)$ or "not at all" $(10 \%, n=2)$.

In summary, learning in the practical projects led to the acquisition of skills in the activity profile of the reference project. However, the outcomes differed between the various sectors. Whereas $55 \%$ and $60 \%$ of respondents said that learnt "much" or "very much", respectively, in the specialist field or in methodology, only $30 \%$ said that they had learnt "much" concerning personal skills, and nobody said that they had learnt "much" or "very much" with regard to social skills. Possibly, the previous experience of the participants was an influential factor here, but more attention should be paid to this in future by the learning process tutors.

\subsection{Hypothesis 4: The Students Develop the Ability to Learn Independently}

The research hypothesised that the students would become better able to learn independently. We asked about the extent to which students sought out sources of information in order to close gaps in their knowledge, and the extent to which they perceived the project studies as an opportunity to learn new things.

Asked "To what extent have you actively used the project studies as an opportunity to learn new things?", $70 \%$ $(n=14)$ answered positively. $40 \%$ of the respondents $(n=8)$ said they were "Very active (intentionally sought a demanding and appropriate project)" and 30\% $(\mathrm{n}=6)$ were "Active (shaping an existing project)". Only 25\% (n=5) were acting "Out of necessity (trying to fit a project to the reference project with the least possible effort)", or "Not at all" $(5 \%, n=1)$.

Asked "How frequently in the practical project did you have to search independently for information or work to close gaps in your knowledge?", the majority of respondents $(60 \%, n=12)$ said that this was necessary either "Often" $(35 \%, n=7)$ or "Very often" $(25 \%, n=5)$. This indicates firstly that the practical project involved challenging activities that require learning (see Hypothesis 3), and secondly that many students independently closed knowledge gaps. But $35 \%$ of respondents $(n=7)$ said they had "Rarely" closed knowledge gaps independently. Only one student replied that this was "Never" the case $(5 \%, n=1)$.

The following comments relate to independent learning:

“...organising the provision of the data was certainly much more difficult and time-consuming. I had to get all the knowledge myself." 
"I used the project studies to get a more fundamental grounding in my own project field and to establish the greatest possible synergies between what was 'newly learnt' in the lectures and the 'old applications' in the company.".

In general, the students tend to find it difficult to estimate their project progress and the learning outcomes and then to document these (cf. Platt, 2014). In the conception and assessment of the project studies, the reflection of their own approach and the key situations encountered play an important role in acquiring sustainable knowledge and checking the learning outcome. Key situations are those situations that delay the project or impede the success of the project, but are related to the organisation rather than the content of the project, e.g. problems making appointments with decision-makers, language problems, or the lack of expertise of participants. In the project studies, reflection is therefore expected in various places, e.g. the regular reflection discussions, the interim presentation, an oral exam, and the documentation at the end of the project.

Asked on which of these occasions the students became aware of the learning outcomes of the practical projects (multiple responses possible), slightly more than half the students $(52.63 \%, \mathrm{n}=10 / 19)$ said that they had been able to make themselves aware of the project progress and the learning outcomes even without the reflection opportunities offered by the project studies. The remainder said that they benefitted from the reflection opportunities. The students found it more difficult to assess project progress and learning outcomes by reflection discussion at the beginning of the project $(26.32 \%, \mathrm{n}=6 / 19)$. The main instrument for the reflection and securing the learning outcomes is the written documentation $(57.89 \%, \mathrm{n}=11 / 19)$. But the final oral exam at the end of the project studies is another important stimulus for reflection $(36.84 \%, \mathrm{n}=7 / 19)$.

In summary, the respondents were able to learn independently in the practical projects. To a large extent, the students initiated learning situations themselves, closed knowledge gaps independently, and were able by means of reflection to assess learning progress and to secure learning outcomes. However, a not inconsiderable proportion of respondents did not make active use of the opportunities for learning, saw hardly any necessity to close knowledge gaps independently, and only found the reflection occasions necessary to a limited extent. In other words, the project studies offered the possibility for independent learning, but did not necessarily ensure this. This was related to the degrees of freedom available in the selection, implementation, and conclusion of the practical projects. The motivation of the students plays a role, as well as ensuring a congenial setting for learning, and these have considerable influence on the selection of a suitable project. These issues have not previously received much consideration in the conception of the project studies.

\subsection{Hypothesis 5: The Personnel in Various Roles (Expert Advisor, Learning Process Tutor, etc.) Offer Essential Support for the Self-controlled Learning of the Students}

The research hypothesised that learning process tutor, expert advisors, line managers, and fellow students and colleagues were a key source of support for the self-controlled learning process of the students. Learning process tutors supervise the project studies, advise the students on methodology, act as contact partners, assess the project documentation, and conduct the reflection discussions with the students. We asked "How important was the support of the learning process tutor in the various project phases?".

According to the respondents, the support of the learning process tutors is important for "Finding a practical project" (77.77\% agreement, $n=14 / 19)$, "Reflecting on the project (reflection discussion)" (73.33\% agreement, $n=11 / 19)$, and "Evaluating the project" $(68.75 \%$ agreement, $\mathrm{n}=11 / 19)$. Fewer found the support important for "Planning the practical project" (46.67\% agreement, $\mathrm{n}=7 / 19)$, "Processing the project" (37.5\% agreement, $\mathrm{n}=6 / 19)$, and "Documentation of the project" (37.5\% agreement, $n=6 / 19)$.

The comments of the respondents suggest that they would appreciate a mentor in the company who could help to find a suitable project and give them backing while the work was in progress: "It would certainly be helpful if from the start EVERY student had an in-house mentor at their side (e.g. the line-manager, an experienced colleague, etc.) who was aware of the contents of the course and could possibly contribute proactively during the preparation (e.g. when searching for a topic)."

The comments of the respondents clearly show the importance of support through the exchanges with other students. There is also an interest in plenary meetings during the project studies and more intensive exchanges with fellow students: "The other students were very reticent and I think it would have been beneficial if we had known who was doing what," or "More meetings together!" and "I would find it good if the results were presented in the course after the conclusion of the project. The interesting thing is not just 'working through' the methodology, but also gaining insights into other topics, approaches and companies. This would promote the exchange within the course."

In summary, the results show that support by a learning process tutor is important throughout the project, i.e. at the 
beginning (finding a project), during the project (reflection), and at the end (evaluation), in order to identify learning outcomes and to secure these. However, this support is not equally important for all fields of activity. There are also phases or activities for which specialist support is helpful. In addition, for certain aspects the support of a mentor and the exchanges with other students are important.

\subsection{Hypothesis 6: Support for the Self-controlled Learning by IT Support (Media or E-learning Environment)}

The research hypothesised that the e-learning environment (Moodle) provides important support for learning. We asked: "Would you have like to have more information or exchange via the learning platform (Moodle)?".

Just over a third of the respondents $(35 \%, \mathrm{n}=7)$ said they would have liked more information or exchange via the learning platform (Moodle). But a large majority $(65 \%, \mathrm{n}=13)$ replied in the negative.

The responses show that the learning platform was hardly used at all for the individual acquisition of specialist knowledge in the course of the project work (classic e-learning). Rather the platform was important for: a) Organising the lectures, b) Exchange with the tutors, and c) Exchanges with the other students. Comments included, concerning a) "It should be possible to hand in the project documentation earlier.", "Examples would have been helpful"; for b) "Since the tutors try to post ALL questions on the Moodle platform (i.e. for everybody), we are usually informed about the most important points. This should be maintained."; and for c) "Perhaps presentation of the topics of fellow students so as to be able to identify similar topics and discuss approaches."

In summary, a classic e-learning platform is not necessary, because the students obtain the necessary knowledge independently from sources in the company (colleagues, books, etc.) or from the Web. However, an online platform is important not only for the formal organisation of the lectures, but also above all for the exchanges with the tutors and with other students.

\subsection{Hypothesis 7: Self-controlled Learning is Supported by A Basis of Specialist Knowledge}

The research hypothesised that the classic lectures on the field of the practical projects in the previous semester provided important specialist support for learning and completion of the practical projects. The participants who had chosen the "Data-Analyst" profile were asked "To what extent did the classic lectures (Data Analytics) help with completing the project?"

All 12 students who had chosen the "Data Analyst" profile reported that most of what they had learnt in the classic teaching was important and useful for the practical project. None of the respondents felt they would have been able to complete the practical project successfully without the preceding lecture course. Interestingly, three of the respondents (15\%) said that because of the classic lectures, the project studies for the topic of "Data Analytics" was not necessary for them to be able to tackle practical problems independently. This must have been a very good, practically-oriented course.

The preceding classic lectures seem to be very important for the success of the practical projects. This is probably also the reason for the low importance attached to an "expert advisor" in a supporting role.

\subsection{Hypothesis 8: Acceptance of the Project Studies}

The research hypothesised that project studies are an attractive form of teaching for the students (acceptance hypothesis). We asked "To what extent did you benefit personally from the project studies?", "What unfavourable conditions did you encounter?", "What could be improved in future?", and "Was it easy to produce the documentation?".

Nearly two-thirds of the respondents $(65 \%, \mathrm{n}=13)$ agreed that the project studies were beneficial to them personally and as a specialist. $40 \%(\mathrm{n}=8)$ agreed that the project studies had helped to demonstrate their competence in the company. And 25\% ( $\mathrm{n}=5)$ said that they had been involved in projects that they otherwise would not have been able to work on.

The most commonly selected options (multiple responses possible) for unfavourable conditions in the company that impeded the work on the practical project were: i) not enough time available $(61.11 \%, \mathrm{n}=11 / 18)$, ii) hard to find a suitable project in my company $(55.56 \%, \mathrm{n}=10 / 18)$, iii) practical project was not possible in the usual work setting $(38.89 \%, \mathrm{n}=7 / 18)$. A lack of support from superiors $(5.56 \%, \mathrm{n}=1 / 18)$ or lack of necessary equipment and materials $(5.56 \%, \mathrm{n}=1 / 18)$ were only mentioned as a problem by one respondent in each case.

The comments of the respondents also indicate the difficulty of finding projects that fit exactly into one semester (i.e. start/finish and duration). In addition, particularly in larger enterprises with projects that have a longer duration, it can be hard to find a suitable project every semester that offers activities for the various roles of the project studies. 
On the other hand, some students were involved in the same company project as IT solution developer in the first semester and then as data analyst in the second semester.

Just over half the respondents $(52 \%, \mathrm{n}=10 / 19)$ said that the documentation of the sub-processes had been easy (arithmetic mean: 2.37). However, a large majority $(84 \%, \mathrm{n}=16 / 19)$ said that some sub-processes had required additional follow-up documentation efforts (arithmetic mean: 1.89). Only 26\% ( $\mathrm{n}=5 / 19)$ reported having trouble thinking up the key situations (arithmetic mean: 2.89), and 68\% (n=13/19) reported that all key situations were easily documented (arithmetic mean: 2.26).

In summary, for more than half the students the learning was made more difficult because the conditions in the company were unfavourable. In particular, this was attributed to a lack of time and the project pressure. The main organisational challenge was finding a suitable practical project in the company which matched the reference project profile and also fitted in the semester timetable. In addition, the majority of the students found the documentation of the sub-processes was difficult and time-consuming.

\section{Conclusions}

\subsection{Main Conclusions for the Concept of the Project Studies}

The concept of project studies that are integrated in the work process has proved successful:

The reference projects were an orientation aid for the majority of respondents when finding a project (Hypothesis 1), and an aid for structuring their learning (Hypothesis 2). The project studies led to the acquisition of skills in the field of the activity profile (Hypothesis 3 ) and the students developed the ability to learn independently (Hypothesis 4). The support for independent learning by people in various roles, in particular a learning process tutor, is very important (Hypothesis 5). Support by an IT environment (e-learning), though less important for the dissemination of specialist contents, is important for the formal organisation and exchanges between those involved (Hypothesis 6). In addition, the preparatory classic lectures are very important for a successful outcome (Hypothesis 7).

All students successfully completed the project studies. The majority of the participants see the project studies as an opportunity to acquire and actively use new knowledge. In addition, a majority felt that it had been beneficial for their development personally and in their field of specialisation. The project studies have also helped to draw attention to their own competence in their company, and students took part in projects in which they otherwise would not have been involved (Hypothesis 8).

The evaluation indicates that the concept of the in-service project studies is viable, represents a success for the students, and enables the desired acquisition of skills and expertise.

\subsection{Optimisation Potential for the Project Studies}

Despite the positive overall assessment of the concept, the results show possibilities for the improvement of both the concept itself and the practical implementation of the project studies.

The greatest challenge for the students was finding a practical project in their company that fit-the reference project and the semester timetable. As a first measure, the project studies have already been separated from the accompanying or preparatory classic lectures. However, additional support is necessary. For example, the range of possible reference projects could be extended (e.g. to include requirements engineers), suitable projects could be provided in other companies, or the completion could be extended over more than one semester.

Positive learning outcomes were identified - in particular with regard to personal and methodological skills - but these were not uniformly spread over the various fields. In particular, social and personal skills were not found to have been increased or insufficient attention was paid to promoting these skills in the project studies. This results in two conclusions: Firstly, the reflection about personal and social skills must be improved and promoted. This is currently implicit in the documentation of 10 key situations (problem, solution, learning outcome), but it could be made explicit by the required documentation of learning outcomes for all the separate fields of expertise. Secondly, learning in the field of social and personal skills should be explicitly required and promoted. This could be achieved by promoting learning in the sectors communications, negotiations, and leadership, corresponding to the objectives of the master's degree programme "Professional IT-Business". This would require an extension of the concept of the in-service project studies with a focus on acquiring and improving social skills.

In this context, there is potential for improving the reflection process. In particular, with regard to the documentation it is noticeable, despite the targeted questions put to them, that the students often tend to report about the project itself rather than reflecting on the decisions they have taken or the key situations (learning outcome). It seems that the students only reflect about their key situations when required to do so for the interim presentation and when 
producing the documentation for the final presentation. However, this delay between the experience and the reflection results in the students formulating apparent reflections, with only the necessary form. In order to be nearer to the process and the situations they encounter, the students should write up their documentation throughout the duration of the project, as they are indeed supposed to. This would then result in a reflective journal (cf. Prior, 2016), which is the intention of the documentation. It may be necessary to agree on additional checks at various points in order to improve the continuity of the reflections.

As a further important improvement, every student should be explicitly assigned a "mentor" in the company who would provide both advice and organisational support. There is already an "expert advisor" in the university, and advice and support is also supposed to be provided by the line manager in the company, and by colleagues. However, this is support is not formalised.

As the analysis of the IT support showed, the students see a real need for contacts with one another. Exchanges between students should be promoted in order to create a mutually beneficial learning community.

\section{Summary and Prospects}

The results of the survey indicate that the concept and the practical implementation of the project studies integrated into the work processes is in principle working as intended. The project studies are practically oriented, because real projects are being carried out in companies. It is process-oriented, because learning is taking place in the course of the work processes. It is directed by experience, because the project work itself is the topic of learning. The project studies are reflected in the interim and final presentations and in the documentation. The process is learner-oriented, because the contents and the work processes are individualised for each project. The entire learning and work process is self-organised with support from the expert advisors and learning process tutors.

The questionnaire responses showed that the reference projects offered a good orientation aid when searching for a project and a good structuring aid for learning. Most of the students responded that they have benefitted personally from the project studies. A majority also responded that after completing the project studies they were better able to carry out the various roles typically involved in the work process. The majority of the respondents saw the project studies as an opportunity that they actively used to gain new knowledge.

The survey provided important insights about the reflection on gains in skills. Whereas a majority said that they have gained in methodological and/or specialist skills, the respondents did not reflect much about gains in personal skills and not at all about improved social skills. It will be necessary to adapt the concept so that the students consciously learn social skills and reflect on this. In future cohorts for the project studies more emphasis should be placed on social skills, in particular concerning communications, negotiations, and leadership. Steps are being taken to extend and optimise the concept and we will report on our progress in a future contribution.

\section{References}

Brand, T. (2014). Evaluation einer arbeitsprozess-orientierten IT-Weiterbildung: IT-Spezialisten. Dissertation, Erfurt: Universität Erfurt.

Buhr, R., Freitag, W., Hartmann, E. A., Loroff, C., Minks, K. H., Mucke, K. \& Stamm-Riemer, I. (Eds.) (2008). Durchlässigkeit gestalten! Wege zwischen beruflicher und hochschulischer Bildung. Münster: Waxmann.

Diller, A. (2010). Von der Sackgasse zur Durchfahrtsstraße. Gleichwertigkeit und Durchlässigkeit im Bildungssystem. Deutsches Jugendinstitut e. V. (DJI)

Dingsoer, T. (2005). Postmortem reviews: purpose and approaches in software engineering. Information and Software Technology, 47(5), 293-303. https://doi.org/10.1016/j.infsof.2004.08.008

Freitag, W., Hartmann, E. A., Loroff, C., Stamm-Riemer, I., Völk, D. \& Buhr, R. (Eds.) (2011). Gestaltungsfeld Anrechnung - Hochschulische und berufliche Bildung im Wandel. Münster: Waxmann.

Fuchs-Kittowski, F., Freiheit, J. \& Siegeris, J. (2017). Project studies integrated into the working processes of companies. In Proc. of the 3rd Int. Conf. on Higher Education Advances (HEAd'17), (pp. 687-695). http://dx.doi.org/10.4995/HEAd17.2017.5353

Götz, K. (1993). Zur Evaluierung beruflicher Weiterbildung. Weinheim: Deutscher Studienverlag.

Junge, H. (2009). Projektstudium als Beitrag zur Steigerung der beruflichen Handlungskompetenz in der wissenschaftlichen Ausbildung von Ingenieuren. Dissertation, Dortmund: Technische Universität Dortmund.

Kleuker, S. \& Thiesing, F.M. (2011). Vier Jahre Software-Engineering-Projekte im Bachelor - ein Statusbericht. In J. Ludewig \& A. Böttcher (Eds.). Poc. of 12. Workshop „Software Engineering im Unterricht der Hochschulen“, 
Vol. 695, 40-44, http://ceur-ws.org/Vol-695/beitrag8-kleuker-thiesing.pdf, Aachen: CEUR-WS.org.

Kruse, E. (2009). Projektstudium und Praxisbezüge im Bologna-Prozess - Reform der Reform? Sozial Extra, 33(1), 42-47.

Lewerentz, C. \& Rust, H. (2001). Die Rolle der Reflexion in Softwarepraktika. 7. Workshop Software Engineering im Unterricht der Hochschulen (SEUH 2001), www.seuh.org/SEUH7_2001/09_Lewerentz.pdf.

Liebehenschel, J. (2013). Software-Engineering Projekte in der Ausbildung an Hochschulen - Konzept, Erfahrungen und Ideen. 13. Workshop Software Engineering im Unterricht der Hochschulen (SEUH 2013), Aachen: CEUR-WS.org, 27-34, http://ceur-ws.org/Vol-956/S1_Paper3.pdf.

Mattauch, W. \& Kubath, S. (2005). Evaluation der arbeitsprozessorientierten Weiterbildung. ISST-Bericht 74/05, Berlin: Fraunhofer ISST.

Platt, L. (2014). The 'wicked problem' of reflective practice: a critical literature review. Innovations in Practice, 9(1). https://doi.org/10.24377/LJMU.iip.vol9iss1article108

Prior, J. R., Arjpru, S. \& Leaney, J. R. (2014). Towards an industry-collaborative, reflective software learning and development environment. Proc. of the 23rd Australasian Software Engineering Conf. ASWEC 2014, Sydney, Australia: IEEE. http://hdl.handle.net/10453/33856

Prior, J. R., Ferguson, S. \& Leaney, J. (2016). Reflection is hard: teaching and learning reflective practice in a software studio. Proc. of the Australasian Computer Science Week ACSW '16, Canberra, Australia, 1-8. https://doi.org/10.1145/2843043.2843346

Schön, D. A. (1983). The reflective practitioner: how professionals think in action. New York: Basic Books. ISBN 046506874X. OCLC 8709452.

Siegeris, J. \& Freiheit, J. (2015). Projekte in der Wirtschaft. In A. Schmolitzky \& A. S. Hauptmann (Eds.). Proc. of 14th Workshop „Software Engineering im Unterricht der Hochschulen“, Vol. 1332, 73-80.

Upchurch, R. \& Sims-Knight, J. (1999). Reflective Essays in Software Engineering. FIE'99 Frontiers in Education. $29^{\text {th }}$ Frontiers in Education Conference, Designing the Future of Science and Engineering Education. Conference Proceedings (IEEE Cat. No.99CH37011, San Juan, Puerto Rico, USA, 1999, pp. 13A6/13-13A6/19 vol.3. https://doi.org/10.1109/FIE.1999.840324

Wottawa, H. \& Thierau, H. (1990). Handbuch Evaluation. Bern: Verlag Hans Huber. 